\title{
Özgün Çalışma
}

\section{Demographic Features of Metastatic Bone Tumors}

\author{
Metastatik Kemik Tümörlerinin Demografik Özellikleri
}

\author{
Coskun Ulucakoy ${ }^{1}$, Aliekber Yapar ${ }^{1}$, Mustafa Cem Şeyhoğlu ${ }^{1}$, Mehmet Ali Tokgöz², \\ İsmail Burak Atalay ${ }^{1}$, Bedii Şafak Güngör ${ }^{1}$ \\ ${ }^{1}$ S.B.Ü. Dr. A.Y. Ankara Onkoloji Eğitim ve Araştırma Hastanesi Ortopedi ve Travmatoloji Kliniği \\ ${ }^{2}$ Nafiz Körez Sincan Devlet Hastanesi Ankara
}

\begin{abstract}
Introduction: Bone is one of the most common metastasis sites for cancers. Metastasis of cancer to the bone rarely results in complete recovery. Bone metastasis; It is associated with various morbidities such as pain, fracture risk and hypercalcemia. As an oncology center, we aimed to present the demographic characteristics of the patients we operated for bone metastasis.

Methods: We retrospectively scanned the archives of patients who were operated for bone metastasis between January 2010 and December 2018 in our clinic. The origin of the metastases, demographic information of the patients, metastasis locations and the surgical procedure performed were recorded.

Results: A total of 477 patients with a diagnosis of metastatic bone tumors, 56\% male, mean age 56.7 $\pm 13.6(11-85)$ years and $68.1 \%$ under 65 years were included in this study. $183(38.4 \%)$ of the patients were pathologic fractured and $13.4 \%$ were diagnosed incidentally. $70.4 \%$ of tumor metastases involve the lower extremity, and the lower extremity is mostly located in the femur $(50.1 \%)$. The first three places where metastases originate are lung (27.5\%), breast (24.1\%) and prostate (14.5\%), respectively. Wide resection and megaprosthesis was applied to the treated patients the most (50\%).

Discussion and conclusion: As a result, the most common cancers that metastasize to the bone are lung, breast and prostate cancer, which are also the most common cancers. Although metastatic bone tumors are preterminal findings, we recommend surgical treatment for these tumors to improve the patient's quality of life, relieve pain and relieve dependency on bed.
\end{abstract}

Keywords: Bone, Metastasis, Lung, Breast, Prostate

\section{ÖZET}

Giriş ve amaç: Kemik, kanserler için en yaygın metastaz bölgelerindendir. Kanserin kemiğe metastazı nadiren tam iyileşme ile sonuçlanır. Kemik metastazı; ağrı, kırık riski ve hiperkalsemi gibi çeşitli morbiditelerle ilişkilidir. Onkoloji merkezi olarak kemik metastazı nedeniyle opere ettiğimiz hastaların demografik özelliklerini sunmayı amaçladık.

Yöntem ve gereçler: Kliniğimizde ocak 2010 ve aralık 2018 yılları arasında kemik metastazı nedeniyle opere edilen hastaların bilgilerini arşivlerden retrospektif olarak taradık. Metastazların neresi kaynaklı olduğu, hastaların demografik bilgileri, metastaz yerleri ve yapılan cerrahi işlem kaydedildi.

Bulgular: Bu çalışmaya \%56'sı erkek yaş ortalaması 56.7 13.6 (11-85) yıl ve \%68,1'i 65 yaş altında olan toplam 477 metastatik kemik tümörü tanısı almış hasta dahil edilmiştir. Hastaların 183'ü (\%38.4) patolojik kırık ile \%13.4'ü ise insidental olarak tanı almıştır. Tümör metastazlarının \%70.4'ü alt ekstremiteyi tutmuştur ve alt ekstremitede ise en fazla femur yerleşimlidir (\%50.1). Metastazların kaynaklandığı ilk üç yer sırası ile akciğer (\%27.5), meme (\%24.1) ve prostattır (\%14.5). Tedavi olarak hastalara en fazla geniş rezeksiyon ve megaprotez (\%50) uygulanmıştır.

Tartışma ve sonuç: Sonuç olarak kemiğe en sık metastaz yapan kanserler, aynı zamanda en sık görülen kanserler olan akciğer, meme ve prostat kenseridir. Metastatik kemik tümörleri preterminal bulgu olmasına rağmen, bu tümörlere hastanın yaşam kalitesini artırmak, ağrısını gidermek ve yatağa bağımlılıktan kurtarmak amacı ile cerrahi tedavi uygulamasını öneriyoruz.

Anahtar Kelimeler: Kemik, Metastaz, Akciğer, Meme, Prostat 


\section{Giriş}

Metastaz; hücreler arası kohezyon kayb1, hücre göçü, anjiyogenez, sistemik dolaşıma erişim, dolaşımda hayatta kalma, lokal bağışıklık tepkilerinin kaçması ve uzak organlarda büyümeyi içeren bir süreçtir.[1] Kemik metastazı, normal kemik yeniden modellemesine birincil müdahale mekanizmasına göre osteolitik, osteoblastik veya mixt olarak sinıflandirılır ve en sik osteolitik metastaz görülür.[2]

Kemik, akciğer ve karaciğerin ardından en sik görülen üçüncü metastaz bölgesidir.[3] Meme ve prostat kanserli hastaların çoğu (yaklaşı \%70) ve akciğer kanserli hastaların önemli bir k1sminda (\%30-40) sonunda kemik metastazları gelişir.[4] Kemik metastazları kendiliğinden kanser ölümlerinden nadiren sorumlu olsalar da, hiperkalsemi, patolojik kırıklar, spinal kompresyon ve kemik ağrısı gibi iskeletle ilișkili olaylara neden olarak önemli morbiditeyle ilişkilendirilirler.[5] Bu nedenle, kemik metastazının kontrolü, kanser tedavisinde kritik bir bileşendir. Bununla birlikte, kemik metastazının mekanizmaları tam olarak aydınlatılamamıştır.

Nadir görülen birincil kemik tümörlerinin yanı sıra, kemik metastazlarının tedavisi artık ortopedik onkoloji iş yükünün büyük bir bölümünü oluşturmaktadır. Bu çalışmada onkoloji merkezi olarak kemik metastazı nedeniyle opere ettiğimiz hastaların demografik özelliklerini sunmayı amaçladık.

\section{Yöntem}

Kliniğimizde ocak 2010 ve aralık 2018 yılları arasında kemik metastazı nedeniyle opere edilen hastaların bilgilerini arşivlerden Retrospektif olarak taradık. Metastazların neresi kaynaklı olduğu, hastaların demografik bilgileri, metastaz yerleri ve yapilan cerrahi işlem kaydedildi. Patolojik olarak kemik metastazı tanısı doğrulanmış ve bu nedenle kliniğimizde opere olmuş olan hastalar çalışmaya dahil edildi. Ameliyat edilmemiş hastalar, palyatif radyoterapiye yönlendirilen hastalar ve arşivlerden kayıtlarına ulaşılamayan hastalar çalışma dışı bırakııldı. Çalışma protokolü, Dr. Abdurrahman Yurtaslan Kurumsal İnceleme Kurulu tarafindan onaylandı. Çalışma Helsinki Bildirgesi ilkelerine uygun olarak yapıld1.

İstatiksel Analiz

Çalışma kapsamında toplanılan verilerin analizinde SPSS 22.0 (Chicago, USA) bilgisayar paket programı kullanıld. Tanımlayıcı istatistikler kısmında kategorik değişkenler sayı, yüzde verilerek, sürekli değişkenler ise ortalama \pm standart sapma ve ortanca (en küçük- en büyük değer) ile sunulmuştur. Sürekli değişkenlerin normal dağılıma uygunluğu görsel (histogram ve olasılık grafikleri) ve analitik yöntemler (Kolmogorov-Smirnov/Shapiro-Wilk testleri) kullanılarak değerlendirilmiştir. Yapılan normallik analizi sonucu sürekli değişkenlerin normal dağılmadığı tespit edilmiştir. Gruplar arasında normal dağılıma uymayan verilerde yapılan karşılaştırma analizlerinde Kruskal Wallis testi kullanılmıştır. Kategorik değişkenler için; gruplar arasında sıklık bak1mından fark olup olmadığı ki-kare testleri kullanılarak karşılaştırmıştır.Bu çalışmada istatistik anlamlılık düzeyi $\mathrm{p}<0,05$ olarak kabul edilmiştir.

\section{Bulgular}

$\mathrm{Bu}$ çalışmaya \%56'sı erkek yaş ortalaması $56.7 \pm 13.6$ (11-85) yıl ve \%68,1'i 65 yaş altında olan toplam 477 metastatik kemik tümörü tanısı almış hasta dahil edilmiștir (Tablo 1). Metastazların kaynaklandığı ilk üç yer sırası ile akciğer (\%27.5), meme (\%24.1) ve prostattır (\%14.5) (Şekil 1). Hastaların 183 'ü (\%38.4) kırık ile \%13.4'ü ise insidental olarak tanı almıştır. Tümör metastazlarının $\% 70.4$ 'ü alt ekstremiteyi tutmuştur ve alt ekstremitede ise en fazla femur yerleşimlidir (\%50.1) (Şekil 2). Femur yerleşimli 239 metastazın \%68.7'si (164 hasta) femur proksimaline, \%16.7'si (40 hasta) femur şaftına ve \%14.6's1 (35 hasta) femur distaline yerleşmiştir. Ekstremite tutulumu yapan 461 kemik metastazının \%56's1 sa ğ taraf yerleşimlidir. Tedavi olarak hastalara en fazla (\%50) megaprotez uygulanmıştır (tablo 1).

Tablo 2'de metastaz yerleşimine göre hasta grupları karşılaştırılmıştır. Yerleşim yerine göre medyan yaşlar benzer bulunmuştur $(p=0.381)$. Vertebra, üst ekstremite ve alt 
Tablo 1. Hastaların demografik ve klinik özellikleri

\begin{tabular}{|c|c|}
\hline Karakteristik & $\begin{array}{c}\text { Total } \\
\mathrm{N}=477\end{array}$ \\
\hline \multicolumn{2}{|l|}{ Yaş, yıl } \\
\hline Ort \pm ss & $56.7 \pm 13.6$ \\
\hline Medyan (min-max) & $57(11-85)$ \\
\hline \multicolumn{2}{|l|}{ Yaşgrup, $n(\%)$} \\
\hline$<65 \mathrm{yll}$ & $325(68.1)$ \\
\hline$\geq 65$ yıl & $152(31.9)$ \\
\hline \multicolumn{2}{|l|}{ Cinsiyet, n (\%) } \\
\hline Kadın & $210(44)$ \\
\hline Erkek & $267(56)$ \\
\hline \multicolumn{2}{|c|}{ Metastazın kaynaklandığı yer, n (\%) } \\
\hline Akciğer & $131(27.5)$ \\
\hline Meme & $115(24.1)$ \\
\hline Prostat & $69(14.5)$ \\
\hline Böbrek & $47(9.9)$ \\
\hline Mesane & $25(5.2)$ \\
\hline Hematolojik Maligniteler & $20(4.2)$ \\
\hline GiS Tümörleri & $29(6.1)$ \\
\hline Diğer** & $41(8.6)$ \\
\hline \multicolumn{2}{|l|}{ Tanı, n(\%) } \\
\hline Takip muayenesi & $230(48.2)$ \\
\hline Patolojik kırık & $183(38.4)$ \\
\hline İnsidental & $64(13.4)$ \\
\hline \multicolumn{2}{|l|}{ Yerleşim yeri, n (\%) } \\
\hline Vertebra & $16(3.4)$ \\
\hline Üst ekstremite & $125(26.2)$ \\
\hline Alt ekstremite & $336(70.4)$ \\
\hline \multicolumn{2}{|l|}{ Taraf $(n=461), n(\%)$} \\
\hline Sağ & $258(56)$ \\
\hline Sol & $203(44)$ \\
\hline \multicolumn{2}{|l|}{ Tedavi, n (\%) } \\
\hline Arif & $96(20.1)$ \\
\hline Parsiyel Protez & $115(24.1)$ \\
\hline Megaprotez & $238(49.9)$ \\
\hline Amputasyon & $28(5.9)$ \\
\hline
\end{tabular}

ekstremite yerleşimli metastazların cinsiyet dağılımları benzerdir $(p=0.071)$. Vertebra yerleşimli olanların \%50'si, üst ekstremite yerleşimlilerin \%37.6's1 ve alt ekstremite yerleşimlilerin \%38.1'i kırık ile tanı almıştır. Gruplar arasında metastaz tanısı alma şekli benzer bulunmuştur $(p=0.671)$. Gruplar arasında metastazın kaynaklandığı organlara göre dağılım incelendiğinde istatistiksel olarak anlamlı fark bulunmamıştır. Alt ekstremiteye en fazla metastaz yapan 3 tümör akciğer (\%27.7), meme (\%23.8) ve prostattır (\%17). Üst ekstremitede ise akciğer (\%29.6), meme (\%24.8) ve böbrektir (\%13.6).

\section{Tartışma}

Kemik metastazları, kemiğin en sık görülen malignitesidir. Bir kanser hücresinin en ölümcül özelliği, metastaz yapabilmesidir. Bu çalışmanın ana bulgusu kemiğe en sık metastaz yapan kanserler ayn zamanda da en sik görülen kanserler olan akciğer, meme ve prostat kanseridir.

Kemik metastazı daha önceden terminal bulgu say1lırken günümüzde gelişen kemoterapi, radyoterapi ve cerrahi teknikler sayesinde, kemik metastazları daha iyi yönetilmektedir. Ortopedik cerrahi tedavinin amacı ağrının giderilmesi ve ağrısız fonksiyon sağlanarak yaşam kalitesini arttırmaktır.[6] İskelet sisteminde en sik metastaz femura (\%61) olmaktadır ve femurun ise en sik $(\% 80)$ pertrokanterik bölgesi tutulmaktadır.[6, 7] Benzer şekilde bu çalışmada da en sık metastaz femura (\%50.1) gerçekleşmiştir ve femur yerleşimli metastazlarında \%68.7'si (164 hasta) femur proksimaline yerleşmiştir.

Önceki çalışmalar, ortaya çıkan patolojik kırıklar için profilaktik fiksasyon alan hastaların, gerçekleşmiş patolojik kırıklar için tedavi edilenlere kıyasla, azalmış ağrı seviyelerine, daha hizlı postoperatif rehabilitasyona ve daha az hastane içi morbiditeye sahip olduğunu göstermektedir.[8] Blank ve arkadaşları [8] yaptıkları çalışmada \%48 hastanın patolojik kırık ile başvurduğunu gösterdiler ancak bizim çalışmamızda bu oran \%38,4'de kalmıștır. Bunun nedeninin onkoloji merkezi olmamı nedeniyle hastaların s1k takibi ve Mirels [9] kriterlerine göre profilaktik olarak opere edilmesi olduğunu düşünüyoruz. $\mathrm{Bu}$ yüzden takip muayenesinde metastaz saptanan hasta sayımız oldukça yüksektir $(\% 48,2)$.

Xu ve arkadaşları yayınladıkları 390 kemik metastazı hastasının ortalama yaşını 55,7 ve kemiğe en sik metastaz yapan kanserleri sirasiyla akciğer $(\% 21,8)$, meme $(\% 13,1)$ ve prostat kanseri $(\% 7,4)$ olarak raporladilar.[7] Benzer şekilde bu çalışmada da 477 metastatik kemik tümörü tanısı almış hastanın ortalama yaşı $56.7 \pm 13.6$ ve kemiğe en sık metastaz yapan kanserler sirasıyla akciğer (\% 


\section{n (\%)}

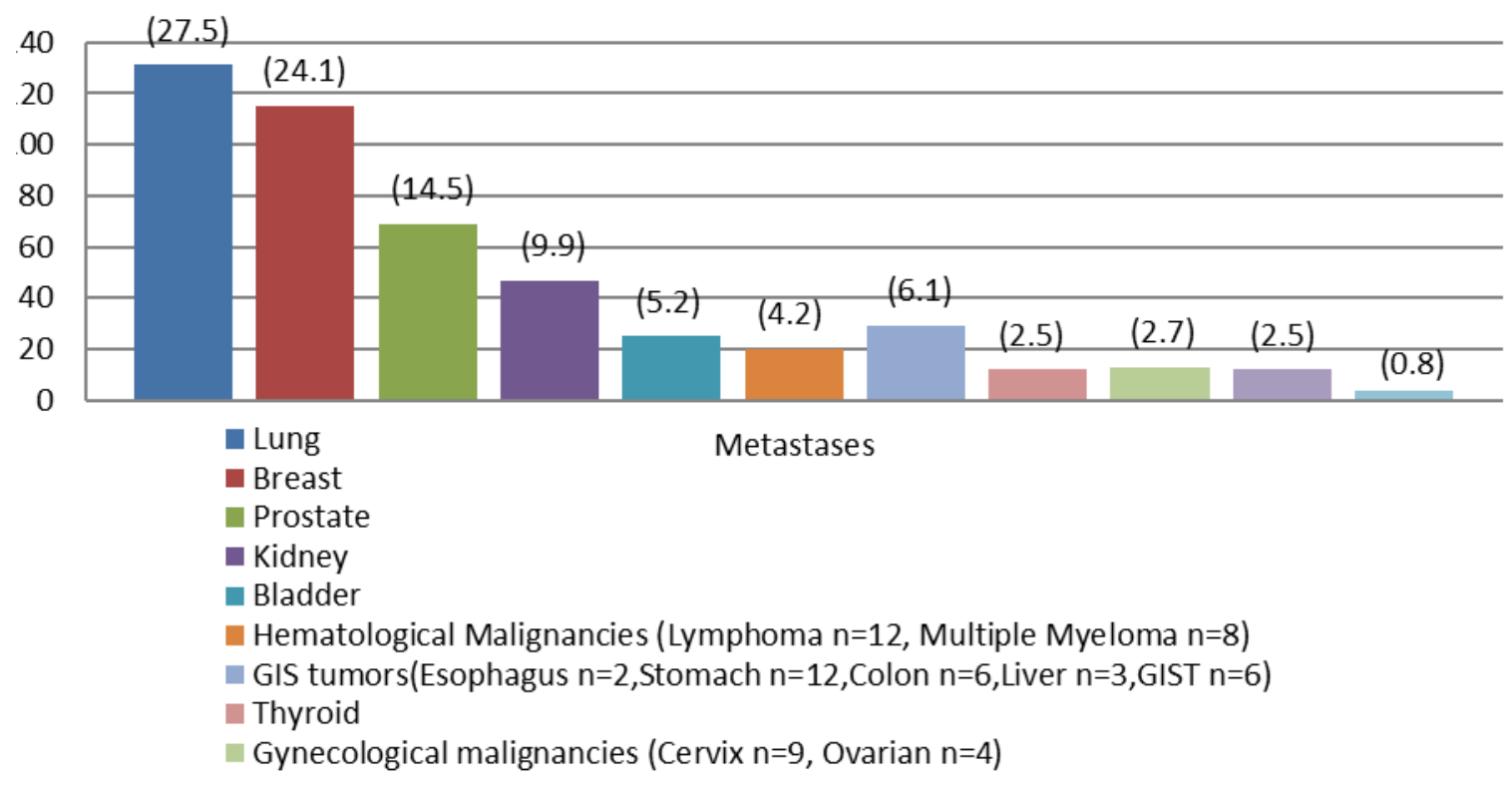

Şekil 1. Kemik metastazlarının kaynaklandığı yere göre dağılımı

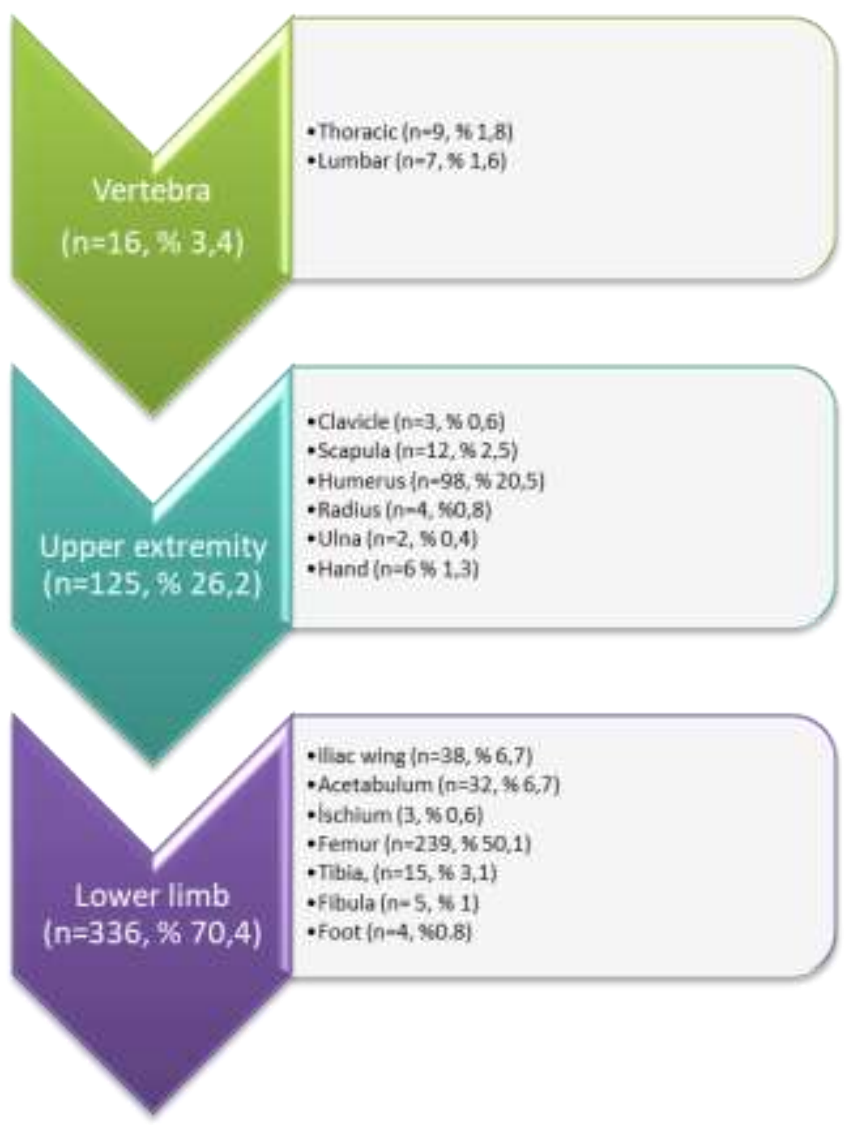

Şekil 2. Yerleşim yerine göre dağılım 
$27,5)$, meme $(\% 24,1)$ ve prostat kanseri (\% 14,5) idi.

Metastatik kemik tümörlerinin tedavisinde amaç hastanın ağrısını gidermek, yaşam kalitesini arttırmak ve lokal kontrolü sağlamaktır.[10] Manabe ve arkadaşları [10] kemik metastazlarının cerrahi tedavisinde hastalara en sik geniş rezeksiyon + megaprotez (\%60) sonrasında sırasıyla geniş rezeksiyon + internal fiksasyon + sementasyon $(\% 31,3)$ ve ampütasyon $(\% 8)$ uyguladılar. Benzer şekilde bu çalışmada da en sık uygulan cerrahi yöntem geniş rezeksiyon + megaprotezdi $(\% 49,9)$. En az ise ampütasyon $(\% 5,9)$ uyguland.

\section{Kaynaklar}

1. Chambers, A.F., et al., Critical steps in hematogenous metastasis: an overview. Surg Oncol Clin North Am, 2001. 10(2): p. 243-255.

2. Coleman, R.E. and J.J. Seaman. The role of zoledronic acid in cancer: clinical studies in the treatment and prevention of bone metastases. in Seminars in oncology. 2001. Elsevier.

3. Coleman, R., Metastatic bone disease: clinical features, pathophysiology and treatment strategies. Cancer treatment reviews, 2001. 27(3): p. 165-176.

4. Cecchini, M.G., et al., Molecular and biological mechanisms of bone metastasis. EAU Update Series, 2005. 3(4): p. 214-226.

5. Mundy, G.R., Mechanisms of bone metastasis. Cancer 1997. 80(S8): p. 1546-1556.

6. Freeman, A.K., V.P. Sumathi, and L. Jeys, Metastatic tumours of bone. Surgery (Oxford), 2018. 36(1): p. 35-40.

Corresponding author e-mail: coskunulucakoy@gmail.com

Orcid ID:

Coşkun Ulucaköy 0000-0002-6991-5511

Aliekber Yapar 0000-0003-2227-2173

Mustafa Cem Şeyhoğlu 0000-0001-6139-1138

Mehmet Ali Tokgöz 0000-0002-4056-3743

İsmail Burak Atalay 0000-0002-6210-4193

Bedii Şafak Güngör 0000-0002-1339-0840

Doi: $10.5505 /$ aot.2021.99705
$\mathrm{Bu}$ çalışmanın bazı kısıtlamaları mevcuttur. Bunlar öncelikle hastaların takip sürelerinin ve sonuçlarının olmamasıdır. Ayrıca Retrospektif bir çalışma olması bir diğer sınırlamadır. Bu çalışmanın güçlü yanı ise literatürde bu kadar hasta sayısı ile yapılan çalışmanın bulunmamasıdır.

Sonuç olarak kemiğe en sik metastaz yapan kanserler, aynı zamanda en sik görülen kanserler olan akciğer, meme ve prostat kenseridir. Metastatik kemik tümörleri preterminal bulgu olmasına rağmen, bu tümörlere hastanın yaşam kalitesini artırmak, ağrısını gidermek ve yatağa bağımlılıktan kurtarmak amacı ile cerrahi tedavi uygulamasını öneriyoruz.

7. Xu, D.-L., et al., Clinical features of pathologically confirmed metastatic bone tumors--a report of 390 cases. Ai zheng= Aizheng= Chinese journal of cancer, 2005. 24(11): p. 1404-1407.

8. Blank, A.T., et al., Is prophylactic intervention more cost-effective than the treatment of pathologic fractures in metastatic bone disease? Clin Orth Rel Res, 2016. 474(7): 1563-1570.

9. Mirels, H., Metastatic disease in long bones. A proposed scoring system for diagnosing impending pathologic fractures. Clin Orth Rel Res, 1989(249): 256-264.

10. Manabe, J., et al., Surgical treatment of bone metastasis: indications and outcomes. Int J Clin Oncol, $2005 ; 10(2):$ 103-111. 